\title{
A note on the punctuated nature of movement paths
}

\author{
Klaus Abels \\ UCL \\ k.abels@ucl.ac.uk \\ Kristine Bentzen \\ University of Troms $\varnothing$ \\ kristine.bentzen@uit.no
}

\begin{abstract}
This paper addresses the question of how a moving item affects the nodes that lie along the path of movement. In particular, we are concerned with the question whether all nodes along the path of movement are affected in the same way or not. We first observe that most arguments that have been given to support the existence of intermediate reconstruction sites do not bear on this issue. We then discuss the logic of what a true argument would look like. Finally, we present three case studies. Two of them (A-reconstruction in Norwegian and VP-ellipsis in Dutch) provide prima facie arguments in favor of a position along the lines of Chomsky $(1973,1986,2000)$, where some but not all nodes along the path of movement are affected by movement.
\end{abstract}

Key words: successive cyclicity, phase theory, reconstruction, A-movement, punctuated path.

\section{Table of Contents}

\section{Introduction}

2. Methodological remark

3. Proposed evidence for punctuated paths (Abels 2003)

4. New empirical evidence: Reconstruction in Norwegian
5. Other kinds of evidence

6. Concluding remarks

References

\section{Introduction}

In this paper we investigate how long-distance dependencies should be modeled. Movement is certainly the most-studied example of a long-distance dependency in language and it is therefore the focus of our investigation.

We take the question whether movement dependencies are mediated in a very local, medium-range local, or long-distance manner to be an empirical issue. There are several different modes of investigation that one could use to pursue this ques- 
tion. They will rely on effects that movement has on the material that has been crossed by movement. Whether such effects exist, where and how they are expressed are all empirical questions. There is no a priori answer to the question of whether the fact that movement occurred in (1) has an effect on the material that has been crossed.

(1) Which book

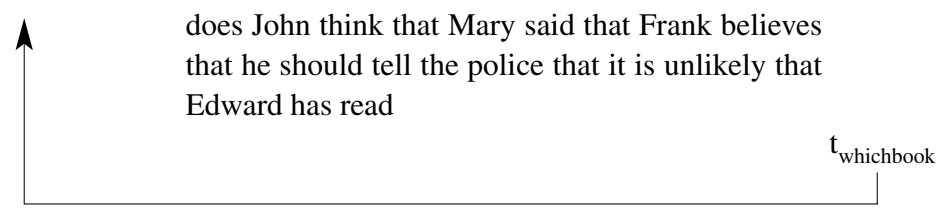

What is clear is that the material that falls between a filler and the corresponding gap in a movement dependency has an effect on that dependency. The most obvious case is provided by island effects. While (2a) is ambiguous between the readings in (2ai) and (2aii), the ambiguity disappears under a minor change of an element along the path of movement, that is, the replacement of that by how in (2b). Such effects of the material crossed on the dependency necessitate some notion of path of movement.

(2) a. When did the boy say that he hurt himself?

(i) When did the boy say [that he hurt himself ?

(ii) When did the boy say [that he hurt himself] ?

b. When did the boy say how he hurt himself?

(i) *When did the boy say [how he hurt himself

(ii) When did the boy say [how he hurt himself]

Example (3) shows that changing that to how along the linear path between filler and gap does not always give rise to the effect seen in (2). This is why paths must be construed in hierarchical terms. All modern theories of grammar make available the relevant notion of path in one way or another.

(3) a. When did [the boy who told his mother [that he hurt himself]] go to bed ?hen?

b. When did [the boy who told his mother [how he hurt himself]] go to bed When?

Given this much, it is unsurprising that the interaction between paths and fillergap dependencies also goes the other way. What lies along the path of movement influences whether and what type of movement is possible. Conversely: Movement along a path seems to exert an influence on what lies along the path. This is shown by familiar effects from word order (e.g., the famous inversion under question for- 
mation in Spanish (Torrego (1983; 1984), Uribe-Etxebarria (1992)) and morphology (e.g. the alternation in the shape of the complementizer in Irish (McCloskey (1979; 1990a; 2002), Noonan (1997)), shown in (4)). Reconstruction effects to places along the path - like the reconstruction effects for binding theory to intermediate landing sites, sometimes called pit-stop reflexives, as discussed in Barss (1986), show yet another type of interaction between path and moving item.

(4) Irish examples from (McCloskey 1990b: 205)

a. Dúirt sé gur bhuail tú é. said he COMP struck you him 'He said that you struck him.'

b. an rud a shíl mé a dúirt tú a dhéanfá the thing COMP $_{t}$ thought I $\operatorname{COMP}_{t}$ said you COMP do-COND-2SNG 'the thing that I thought you said you would do'

We here introduce a distinction between two types of theories that comes from Abels (2003). Abels distinguishes between punctuated and uniform paths. A path will be called punctuated if some nodes along it are affected by having been moved through while others are not. A path will be called uniform if all nodes along it are affected in the same way. HPSG, Categorial Grammar, and the theory of the Configurational Matrix are examples of theories where paths are treated uniformly. All nodes along the path are affected - and are affected in the same way. Tree Adjoining Grammars offer a theory that is uniform in a very different way: the nodes along the movement path remain uniformly unaffected.

On the other hand, theories in the narrower Chomskyan tradition postulate punctuated paths. This is true of the Extended Standard Theory of the seventies, where only selected nodes, namely the COMP nodes, along the path were affected. This is true of the Barriers theory, where intermediate traces are created in some phrases along the path of movement (VP and CP) but not in others (IP, NP, PP). The same is true, of course, also of the more recent idea of little vP and CP as 'phases.' Phases are characterized - among other things - by providing specifier positions that act as intermediate landing sites for movement; such specifier positions are assumed to be absent in non-phasal phrases. Even in theories where landing sites are quite close together, as for example in Chomsky and Lasnik (1993), Takahashi (1994), Boeckx (2001; 2008) and Bošković (2007), it still remains true that only the maximal projections along the path are affected, but not intermediate projections. ${ }^{1}$

1. Abels (2003) calls theories where the nodes affected by movement are very close together quasi uniform. The reason for this terminological move was the assumption that it would be empirically very difficult to distinguish quasi uniform theories from uniform theories. It seemed easier at the time to distinguish punctuated theories with wide gaps between the affected nodes from the other two types. We believe now that this impression was wrong. 
Most so-called cyclicity effects have no bearing on the question of punctuated versus uniform paths. The Irish data, for example, are compatible with various uniform and punctuated analyses.

Bouma et al. (2001) treat the alternating element as a preverbal particle rather than a complementizer, but this does not alter the logic of the situation. They use a theory where paths are uniform, HPSG, and make the shape of the alternating element depend on whether its sister has an empty or a non-empty SLASH value.

The analyses of the same alternation that McCloskey has given over the years (with the exception of McCloskey (1979)) treat the alternation in terms of a punctuational model where the shape of the complementizer depends on a local relation with the moving element at various stages of the derivation. The moving element itself "leapfrogs" as it were, leaving many nodes along the path completely untouched.

Finally, we can give a uniform non-local account of the alternation. We could assume the following realization rule for the complementizer in Irish. ${ }^{2}$

(5) a. Realize an instance of the complementizer $\mathrm{C}^{0}$ as $a L$ (leniting) if there is a movement chain in which the head c-commands $\mathrm{C}^{0}$ and $\mathrm{C}^{0} \mathrm{c}$-commands the foot. Otherwise

b. realize an instance of the complementizer $\mathrm{C}^{0}$ as $a N$ (nasalizing) if it is locally c-commanded (Spec-Head) by an operator. Otherwise

c. realize an instance of the complementizer $\mathrm{C}^{0}$ as go.

Similar considerations make even fairly complex arguments that demonstrate the existence of a particular reconstruction site silent on the issue of punctuated versus uniform movement paths; thus, while (6) provides evidence for the existence of a reconstruction site for the topicalized noun phrase in between the position of the subject and the object of ask, it does not bear on the question whether all nodes between the subject and object of ask can serve as reconstruction sites or just some.

(6) a. [The papers that he ${ }_{1}$ wrote for Ms. Brown 2$]$ every student ${ }_{1}\left[{ }_{V P} t^{\prime}\right.$ asked her ${ }_{2}$ to grade $t$.

b. $*\left[\right.$ The papers that he ${ }_{1}$ wrote for Ms. Brown $\left.{ }_{2}\right]$ she $_{2}\left[\mathrm{t}\right.$ ' asked every student ${ }_{1}$ to revise t]. (Fox 2000: 10-11)

In this paper we take up the empirical challenge. In section 2 we lay out some of the tools we have for probing the nature of movement paths. In sections 3 and 4 we discuss some empirical support in favor of punctuated movement paths from variable binding in English and reconstruction in Norwegian, respectively. Section

2. There might be an indirect argument here against a non-local treatment. The rules (5a) and (5b) are not ordered by the elsewhere principle unless 'c-commands' is replaced by 'locally c-commands' in the formulation of the first condition. 
5 provides a different argument for punctuated paths based on ellipsis, and section 6 concludes the paper.

The aim of this paper is modest. We would like to point out that the question of the punctuated vs. uniform nature of movement paths is an empirical one that cannot be decided by a priori reasoning. As shown in the preceding paragraphs, it cannot be decided by providing evidence for the existence of reconstruction sites in one place or another either. Not to have taken note of this point is an important shortcoming of much of the literature on successive cyclicity from the 70s onward. What needs to be done instead is to investigate whether movement paths are affected uniformly or not. Whether we ultimately want to argue for uniform or punctuated paths, we need to look for specific kinds of inhomogeneous reconstructive behavior in the data. If they exist, this might vindicate something like the position taken in Chomsky (1973), Chomsky (1986), and Chomsky (2000), if not, this would vindicate models postulating uniform paths.

\section{Methodological remark}

To give a true argument for the punctuated nature of paths, we need to show that some nodes along the path are unaffected by movement while others both below and above them are affected. As noted for example in Abels (2003) and Boeckx (2008), the great confidence with which punctuational models are often proposed is not matched by an equal amount of empirical evidence for them. We will first address the fairly simple logic of the situation in this section and then move on to three empirical case studies in the following sections.

\subsection{Is lack of reconstruction a valid argument for punctuated paths?}

The putative arguments for the punctuated nature of movement paths mentioned in the introduction can all be construed as arguments from reconstruction: reconstruction for (local) agreement in the case of Irish complementizer agreement and reconstruction for binding and scope in the case of topicalization. What these arguments seem to show is that some nodes along the path of movement are affected because they are reconstruction sites. These arguments do not bear on the question of the punctuated nature of paths, since they are fully compatible with a theory where all nodes along the path are affected.

To give a true argument for the punctuated nature of paths, we therefore need to show that some nodes along the path are unaffected by movement while others are affected. As noted for example in Abels (2003) and Boeckx (2008), there is little if any convincing empirical evidence to argue for the absence of reconstruction to a particular position. The situation is complicated by the fact that even the lack of reconstruction (construed in the broadest sense) to a particular position is not direct evidence for the punctuated nature of paths; a node might have been affected by movement, yet, for independent reasons, we might be unable to show this. Boeckx (2008: 58) expresses this clearly towards the end of the following quotation: 
"Whereas the copy theory of movement readily accounts for reconstruction by involving the interpretation of unpronounced copies, we cannot conclude from this that if no reconstruction effect is found, no copy is available at the relevant site. All we can conclude from the absence of reconstruction is either that there is no copy present, or that a copy was created, but for some (perhaps interpretive) reason cannot be interpreted in the relevant position."

A well-known case where reconstruction is blocked is provided by the readings that quantified arguments get when they are extracted from a weak island. Consider example (7). There is no reconstruction of the restriction of the wh-phrase into the weak island (Longobardi 1991, Cinque 1990, Cresti 1995, Frampton 1999), hence, only the de re reading of the $w h$-moved NP is available. This could be taken to indicate that there is no copy of the $w h$-phrase inside of the weak island. This conclusion would be rash however - and a different explanation for the lack of reconstruction has to be sought - since there is reconstruction into the island for other properties such as binding (Cinque 1990, Starke 2001).

(7) a. How many people do you think that John invited?

b. How many people do you wonder whether to invite?

What is striking about this case and others like it is that while reconstructive behavior is not uniform along the entire length of the path, it is monotonic: for some reconstructive property $\mathrm{P}$, the path is cut into two contiguous parts, one of which allows reconstruction, while the other one disallows it.

Let us make a terminological distinction between uniform, (non-uniform) monotonic, and punctuated reconstruction patterns.

Uniform reconstruction patterns are those where no two points along a path can be distinguished by their reconstructive behavior, i.e., either reconstruction is possible to every point along the path or to none. In Figure 1 this would correspond to a situation where either reconstruction is possible at all points along the path in between any two elements, i.e., where reconstruction to all of $\alpha, \beta, \gamma$, and $\delta$ is possible, or else where no reconstruction is possible at all, i.e., none of $\alpha-\delta$ are available for reconstruction.

On the other hand, non-uniform monotonic patterns are those where the path can be divided into two contiguous parts, one of which allows reconstruction while the other one disallows it. In Figure 1 this would be the case if reconstruction was available to $\alpha$ and $\beta$ but not to $\gamma$ and $\delta$. The weak island extraction facts are a case of this sort, where reconstruction of the nominal restriction is possible above the island inducing element but not below it. ${ }^{3}$

A punctuated reconstruction pattern is one where there are sites for reconstruction both above and below sites that do not allow reconstruction. In Figure 1, we would speak of a punctuated reconstructive pattern if $\alpha$ and $\delta$ were possible

3. Notice that uniform reconstructive patterns are also monotonic, hence the modifier 'non-uniform.' 


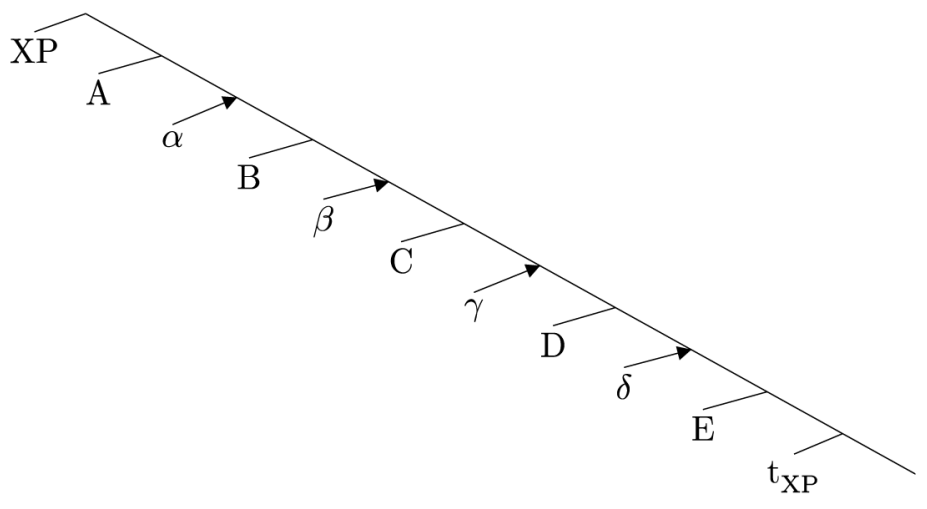

Figure 1. Path between $t_{X P}$ and XP with four distinct points along the path, $\alpha-\delta$.

reconstruction sites while $\beta$ and $\gamma$ were not, if reconstruction sites alternated with non-reconstruction sites, etc.

Different theories of movement give rise to different expectations regarding reconstructive patterns. Uniform theories of movement predict uniform reconstructive patterns and need to invoke additional assumptions to handle non-uniform monotonic and punctuated reconstructive patterns. Theories of movement that predict punctuated movement paths on the other hand give rise to the expectation that we should find punctuated reconstructive patterns, and they need additional assumptions to deal with non-uniform monotonic and uniform patterns.

Therefore, if a punctuated reconstructive pattern can be found, this provides a prima facie argument for a punctuated theory of movement paths. Such an argument will fall if an independent reason can be found why reconstruction to particular points along the path is blocked (the second disjunct in the quote from Boeckx above) or if reconstructive behavior for different properties does not align, i.e., if a position is not a scope reconstruction site but it is a binding reconstruction site, etc.

Since these matters have not been investigated in detail before, we will present two case studies of reconstructive patterns, the second of which will turn out to provide a prima facie argument for punctuated paths. We also sketch the logic of other potential cases which should be but have not been investigated. We are not able at this moment to tell whether our prima facie argument will eventually fall for one of the two reasons mentioned above.

\subsection{Scope: The best tool we have}

Scope is the best tool we have for probing the punctuated versus uniform nature of movement paths. When two scope-bearing elements, whose relative scope we can independently determine, lie along a movement path, it is in principle a simple 
task to find out whether the moving element can scope below, above, and/or in between them. Arbitrarily fine spatial distinctions can be made this way.

Nissenbaum (2001) discusses a case of roughly this shape in his thesis. What is at issue below is the fact that there must be a restricted number of intermediate copies/traces and a correspondingly restricted number of $\lambda$-binders. Nissenbaum observes that in a situation with several VP adjuncts, if one of them contains a parasitic gap, then all the ones closer to the VP must also contain a parasitic gap. ${ }^{4}$ This is schematized in (8).

$$
\begin{aligned}
& \text { Nissenbaum }(2001) \text { : } \\
& \text { V ([ ...PG ]) }([\text {...PG }])[\text {...no PG] }(*[\ldots P G])([\ldots \text {... PG }])
\end{aligned}
$$

The examples in (9) illustrate this generalization. If both adjuncts contain a parasitic gap, as in (9a), no problem arises. If neither of them does, as in (9b), still no problem arises. However, when only one of the adjuncts contains a parasitic gap it must be the one closer to the verb, as the contrast between $(9 \mathrm{c})$ and $(9 \mathrm{~d})$ illustrates.

(9) Examples from (Nissenbaum 2001: 72-73)

a. Who did you $\left[_{V P}\left[{ }_{V P}\left[{ }_{V P}\left[_{V P}\right.\right.\right.\right.$ praise to the sky $\left.{ }_{V P}\right]$ [after criticizing $\left.P G\right]$ ${ }_{V P}$ ] [in order to surprise $\left.\left.P G\right]_{V P}\right]$ ?

b. Who did you $\left[_{V P}\left[{ }_{V P}\left[{ }_{V P} \text { praise to the sky }{ }_{V P}\right] \text { [after criticizing him }\right]_{V P}\right]$ [in order to surprise the poor man $\left.{ }_{V P}\right]$ ?

c. Who did you $\left[_{V P}\left[{ }_{V P}\left[{ }_{V P} \text { praise to the sky }{ }_{V P}\right] \text { [after criticizing } P G\right]_{V P}\right]$ [in order to surprise him $\left.{ }_{V P}\right]$ ?

d. *Who did you $\left[_{V P}\left[{ }_{V P}\left[{ }_{V P} \text { praise to the sky }{ }_{V P}\right] \text { [after criticizing him }\right]_{V P}\right]$ [in order to surprise $\left.P G]_{V P}\right]$ ?

Nissenbaum accounts for these facts by assuming that in successive cyclic movement an intermediate copy, interpreted as a variable of type $<\mathrm{e}>$ and a $\lambda$ binder, which gives rise to an abstract of type $<$ e, $t>$, are created. Clauses without parasitic gaps are of type $<\mathrm{t}\rangle$, while those containing a parasitic gap are of type $<e, t>$. This allows a straightforward explanation of Larson's generalization in terms of a type mismatch, as shown in Figure 2. If a clause with a parasitic gap adjoins too high, a type mismatch occurs leading to a failure of interpretation higher up in the tree. The same is true if a clause without a parasitic gap adjoins too low. Adjunction sites that are even lower than the $\lambda$-binder will have to be ruled out, presumably by syntactic stipulation. ${ }^{5}$

4. The observation as relating to Heavy NP Shift is due to Larson (1988).

5. To complete the argument, multiclausal structures have to be considered. To the extent that Nissenbaum discusses them, they indicate that Larson's generalization is neither linear nor monotonic but holds separately of each VP along the path of movement, i.e., the pattern is punctuated. 


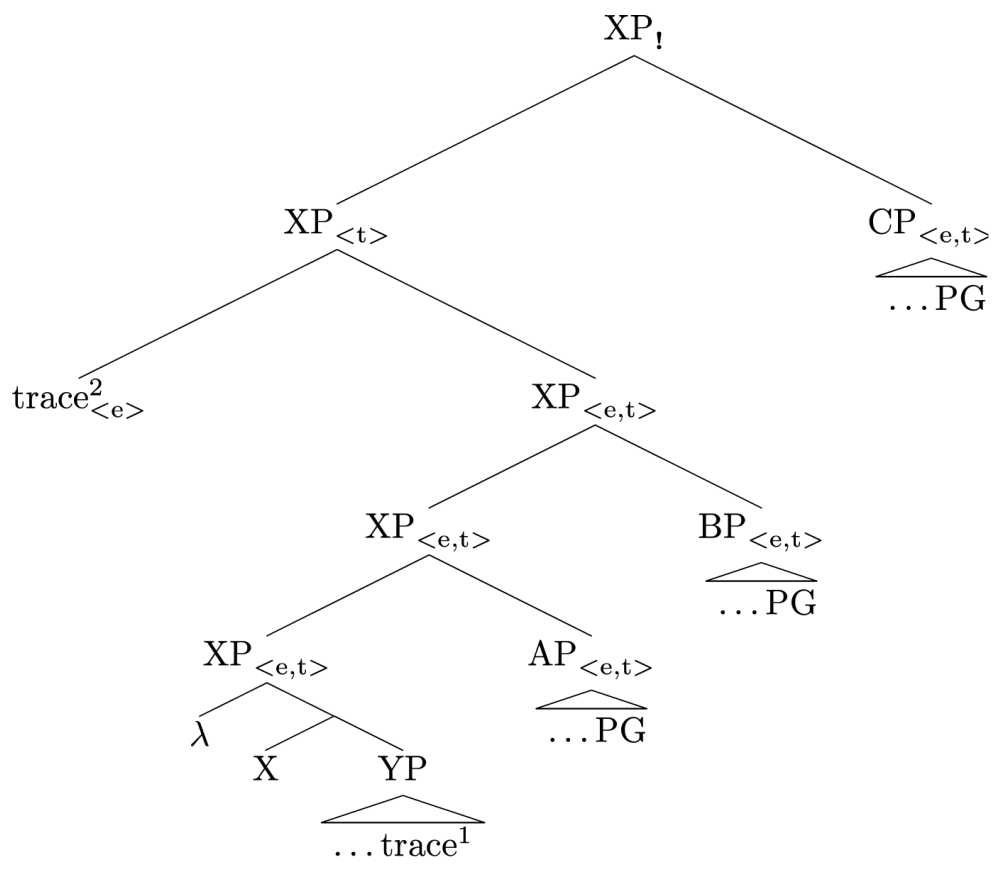

Figure 2. Type-annotated tree illustrating Nissenbaum's account of (8).

To the extent that it is empirically and theoretically sound, Nissenbaum's analysis provides an argument for the punctuated nature of paths. His account of Larson's generalization relies crucially on a distinction being made between nodes that lie in between the intermediate copy/trace of movement and the $\lambda$-binder and those above the intermediate copy/trace of movement. A uniform theory of paths, where all nodes are treated the same way - Nissenbaum himself mentions the slashed categories of HPSG - has no way of making such a distinction. Hence, not every node along the path can be treated as identically affected by the movement, hence, we have a prima facie argument for punctuated paths.

\subsection{Variable Binding and Binding Theory}

We now turn to the interaction of the binding theory with variable binding and scope. These should also in principle allow us to construct arguments in favor of missing intermediate landing sites.

\subsubsection{Condition $C$ and Scope for Binding}

Certain interactions between scope for binding and condition $\mathrm{C}$ of the binding theory are potentially informative regarding the punctuated nature of paths. Recall 
examples (6), repeated as (10). In the good example, (10a), the quantifier that binds into the moved phrase c-commands that the pronoun her, which potentially interacts with the R-expression in the moved phrase via condition $\mathrm{C}$. In the bad example, (10b), the c-command relations are reversed. The pronoun c-commands the quantifier. Hence, if the quantifier is to bind into the moved phrase so will the pronoun.

(10) a. [The papers that he ${ }_{1}$ wrote for Ms. Brown $\left.{ }_{2}\right]$ every student ${ }_{1}\left[{ }_{V P} t^{\prime}\right.$ asked her ${ }_{2}$ to grade t].

b. $*\left[\right.$ The papers that he ${ }_{1}$ wrote for Ms. Brown $\left.{ }_{2}\right]$ she $_{2}[\mathrm{t}$ ' asked every student 1 to revise t]. (Fox 2000: 10-11)

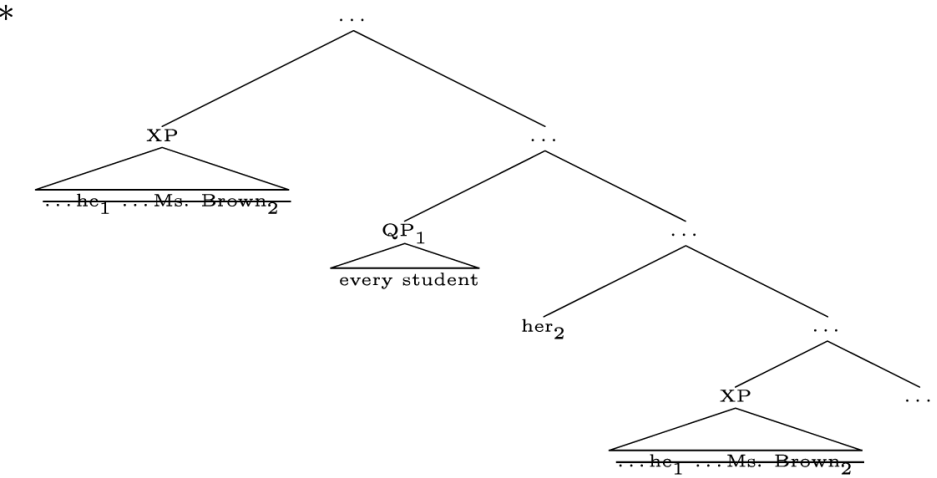

Figure 3. A hypothetical unacceptable variant of (10a).

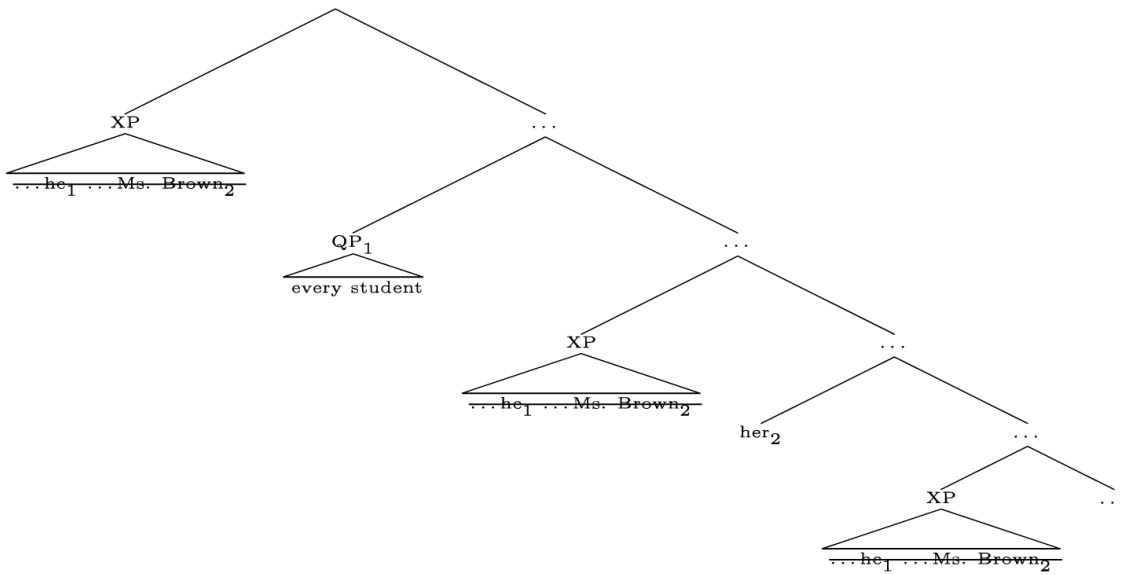

Figure 4. Hypothetical repair of the example in Figure 3. 
Now, if an example just like Fox's acceptable example, (10a), could be found that was unacceptable so long as the quantifier and the pronoun were structurally very close, but which improved once the structural distance between them was increased, this would be an argument for the punctuated nature of paths.

In the hypothetical case, represented in Figure 3, there is no possible intermediate node from which the moving element could take scope below the quantifier - which it needs to to allow binding into XP - and above 'her ${ }_{2}$ ' - which it needs to to avoid a violation of Binding Condition $\mathrm{C}$. This situation would then be remedied if the quantifier and the pronoun are structurally separated, as in Figure 4. This would make available an intermediate reconstruction site.

Whether such cases exist, needs to be investigated.

\subsubsection{Locality of Condition A}

A second class of cases involves binding condition A. The locality inherent in Principle A of binding theory allows us to probe for lack of intermediate landing sites. Given that, in a language like English, binding condition A roughly requires the antecedent and the anaphor to be clausemates, condition A is a relatively coarse measure of the absence/presence of intermediate landing sites.

The relevant structure is given below in Figure 5. In the structure there is an anaphor contained in a moving phrase, XP. Under the punctuated path hypothesis, there would be various traces/copies of XP, concretely in Figure 5 there are three. For each of the copies there is a certain local domain within which the anaphor has to be bound if that copy is to be involved. This is schematized in Figure 5 by the nodes labeled DomainP which are cosuperscripted with the trace/copy for which they

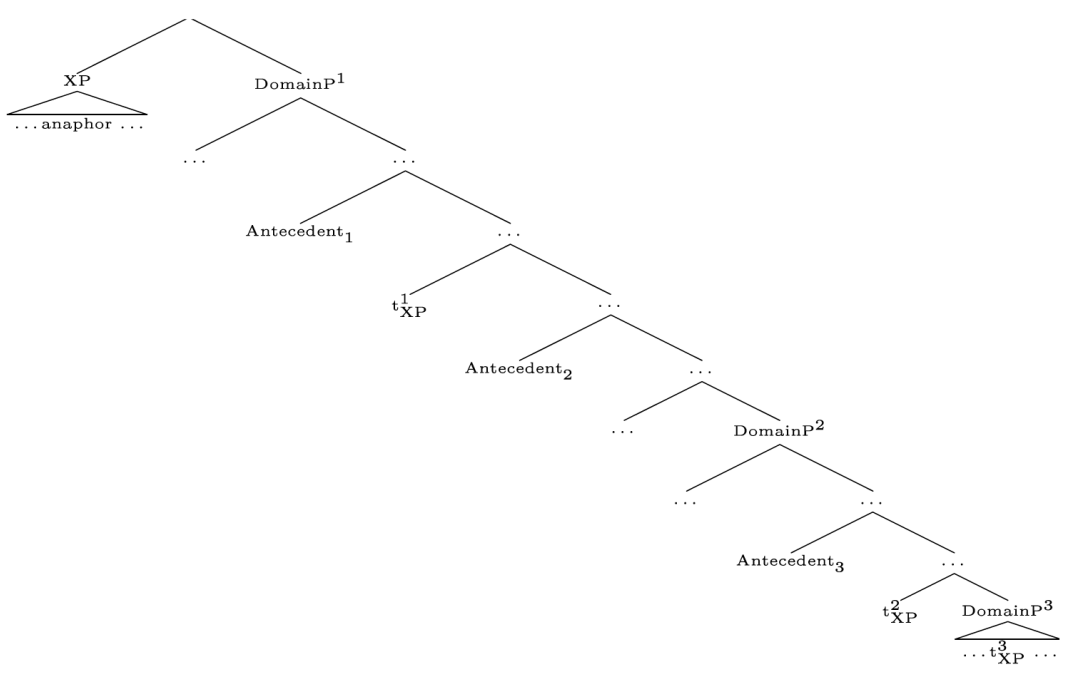

Figure 5. Schematic representation of the argument in Abels (2003). 
constitute the binding domain. Finally, there are various potential antecedents for the anaphor.

DomainP indicates the maximal possible binding domain of the anaphor within the moving constituent from the closest trace position. What we would test in this configuration is lack of binding because no sufficiently local intermediate trace position exists. This is illustrated in Figure 5, where pit-stop binding by Antecedent ${ }_{3}$ and Antecedent ${ }_{1}$ ought to be possible, while the same should not hold for Antecedent ${ }_{2}$.

Abels (2003) attempts an argument of this shape, to which we return.

\subsubsection{Scope and Variable Binding}

Similarly we can investigate the interaction of scope and variable binding to give us information about the absence of sites for intermediate reconstruction. We will use this very logic later on in the examples from Norwegian.

The idea is the following. Suppose a moved quantifier can take either wide or narrow scope with respect to another scope-bearing element. If the quantifier needs to take scope below the other scope-bearing element and simultaneously bind into an even lower XP, this will only be possible if there is a possible site for reconstruction in between the two but not if there is no such reconstruction site between them. The situation is illustrated in Figures 6 and 7, where the trace between the scope-bearing element and XP in Figure 7 marks the availability of a reconstruction site while its absence in Figure 6 indicates the absence of such a site. The absence of a low-scope reading with binding into XP would, we believe, count as evidence for the punctuated nature of paths.

To complete the argument, one would have to show that the different properties cluster: If the positions involved in morphosyntactic changes under movement were limited in a cross-linguistic perspective, if they coincided with the positions cru-

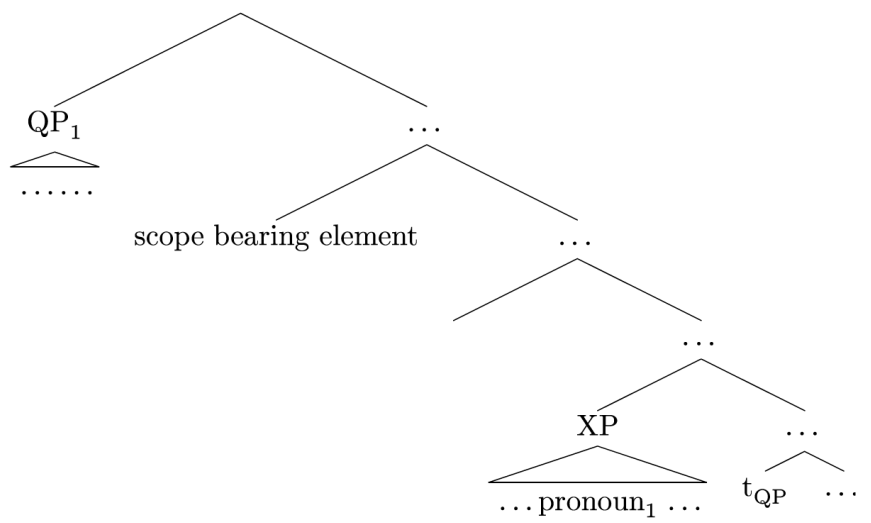

Figure 6. Low scope and high binding is impossible without an intermediate trace. 


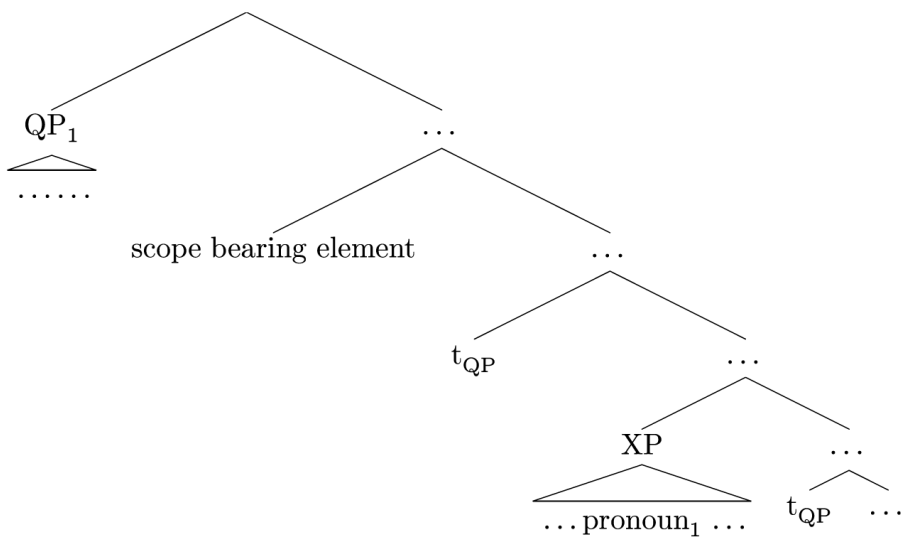

Figure 7. Low scope and high binding is possible with an intermediate trace.

cially involved in locality theory, and if those same nodes were the only possible reconstruction sites, then this would constitute very strong evidence for the punctuated nature of paths. For the moment our knowledge, especially that of lacking reconstruction sites, is too limited to warrant such conclusions.

\section{Proposed evidence for punctuated paths (Abels 2003)}

In this and the next section we present two case studies that aim at providing evidence for punctuated reconstruction patterns. The first set of data comes from Abels (2003), but, as we will see, the proposed evidence is problematic. Recall from the previous section that we suggested that the locality of anaphor binding might be informative with respect to determining whether or not an intermediate position is available along the path. It is of course well-known that anaphors may be bound at various points along the movement path (cf. Barss 1986). This is illustrated in (11). In (11a), the anaphor himself within the wh-phrase is bound by John in its surface position, whereas in (11b), herself is bound in a position below Mary, presumably its base position. In (11c) himself is bound by John in some intermediate position.

(11) a. John $_{i}$ wonders which pictures of himself ${ }_{i}$ Mary likes.

b. John wonders which pictures of herself Mary $_{i}$ likes.

c. Which pictures of himself ${ }_{i}$ does Jane believe (that) John ${ }_{i}$ thinks (that) she likes?

However, these examples do not tell us anything about whether paths are uniform or punctuated. A clause like (11c) can be construed with either a uniform or a punctuated path, as shown in (12)-(13). 
(12) Uniform path:

[which picture of himself $]_{i}\left[\ldots\right.$ John $\ldots{ }_{v P} \mathrm{t}_{i} \mathrm{v}^{\mathrm{o}}\left[_{V P} \mathrm{t}_{i}\right.$ thinks $\left[_{C P} \mathrm{t}_{i}\right.$ that $\left[_{T P} \mathrm{t}_{i}\right.$ Mary [...]]]]]]

(13) Punctuated path:

[which picture of himself $]_{i}\left[\ldots\right.$ John $\ldots\left[_{v P} \mathrm{t}_{i} \mathrm{v}^{\mathrm{o}}\left[_{V P}\right.\right.$ thinks $\left[_{C P} \mathrm{t}_{i}\right.$ that $\left[_{T P}\right.$ Mary $[\ldots]]]]]]$

Crucially, though, Abels (2003) provides a context in which binding of a moved anaphor is not possible. Consider the pair in (14). In (14a), the experiencer of seem can bind the anaphor in the moved $w h$-phrase. In (14b), when seem is used as a raising verb, however, this is not possible.

(14) a. Which picture of himself ${ }_{i}$ did it seem to John ${ }_{i}$ that Mary liked?

b. *Which picture of himself ${ }_{i}$ did Mary seem to $\mathrm{John}_{i}$ to like?

Abels (2003) argues that this is because in (14a) there is an available [Spec, CP] position below John, which the wh-phrase moves through or adjoins to, and this position is local enough for John to bind the anaphor, as shown in (15).

(15) [Which picture of himself $]_{i}$ it $\left[_{V P 1}\right.$ seem $\left[_{V P 2}\right.$ to John $\mathrm{t}_{\text {seem }}\left[_{C P} \mathrm{t}_{i}\right.$ that $\left[_{T P}\right.$ Mary $\left[{ }_{V P 3} \mathrm{t}_{i}\right.$ liked $\left.\left.\left.\left.\left.\mathrm{t}_{i}\right]\right]\right]\right]\right]$

In (14b) on the other hand there is no such position available, as illustrated in (16). The raising infinitive is taken to be a TP rather than a CP, and following Chomsky (1986), adjunction to TP is not allowed. Furthermore, the wh-phrase could not have moved through [Spec, TP], as the trace of Mary occupies this position.

(16) [Which picture of himself $]_{i}$ Mary $\left[_{V P 1}\right.$ seem $\left[_{V P 2}\right.$ to John $\mathrm{t}_{\text {seem }}\left[_{T P} \mathrm{t}_{\text {Mary }}\right.$ to $\left[{ }_{V P 3} \mathrm{t}_{i}\right.$ like $\left.\left.\left.\left.\mathrm{t}_{i}\right]\right]\right]\right]$

Abels takes this as evidence for punctuated paths; that is, the moving element only makes intermediate stops in certain positions: in CP but not in TP.

We are aware of two potential challenges to this argument. Gereon Müller ${ }^{6}$ makes the following observation concerning the two crucial examples: While in (14a) only a single phrase, the $w h$-phrase, is moving, there are two moving phrases in (14b). In the latter, the $w h$-phrase and the raising subject move along overlapping paths. This raises the possibility that there is an intermediate landing site both for the $w h$-phrase and the subject above the embedded [Spec, TP] position but below the experiencer, as schematized in (17).

6. Personal communication to the first author and in his presentation at the DGfS workshop on Local Modeling of Non-local Dependencies (Bamberg, Feb. 2008). 
(17) [Which picture of himself $]_{i}$ Mary $\left[_{V P 1}\right.$ seem $\left[_{V P 2}\right.$ to John $\left[\mathrm{t}_{\text {Mary }}\left[\mathrm{t}_{i}\left[\mathrm{t}_{\text {seem }}\left[_{T P} \mathrm{t}_{\text {Mary }}\right.\right.\right.\right.$ to $\left[{ }_{V P 3} \mathrm{t}_{i}\right.$ like $\left.\left.\left.\left.\mathrm{t}_{i}\right]\right]\right]\right]$

Notice that all traces of the wh-phrase in (17) that are c-commanded by the experiencer are also c-commanded by the subject or a trace thereof. Notice further that in every single case the subject or its trace are closer to (the trace of) the whphrase than the experiencer. Assuming a binding theory strictly in terms of closest c-command, the subject would always be the relevant binder of the anaphor in (17). Given that the subject does not raise in (14a), there is an intermediate position where the experiencer is the closest potential binder for the anaphor. Hence, Müller argues, the contrast between (14a) and (14b) does not provide evidence for the punctuated nature of movement paths.

This objection, of course, is only as strong as the binding theoretic assumptions that it rests upon, namely, that anaphors in English can only be bound by the closest c-commanding antecedent. This assumption is problematic, as the examples in (18) illustrate. As has been known at least since Barss and Lasnik (1986), the DP object in such examples c-commands into the PP, (18a). However, and this undermines the strength of Müller's objection, in example (18b) the subject can antecede the anaphor despite the fact that it is not the closest potential c-commanding antecedent, which is the DP object as in (18a).

(18) a. Mary explained the man to himself.

b. Mary explained the man to herself.

A second more damaging problem for the argument is pointed out by Boeckx (2008). If the contrast between (14a) and (14b) was only due to the presence versus absence of a CP below John, then we would expect anaphor binding to be possible also into a more deeply embedded CP. Thus, all examples in (19) should be fine. However, (19c) is ungrammatical. It seems that reconstruction of the moved wh-phrase to an intermediate landing site below the experiencer in a raising construction is blocked in general, i.e., in the terminology of the previous section, we are dealing with a case of monotonic reconstruction. We argued that such phenomena cannot be used to argue for the punctuated nature of movement paths.

(19) a. Which picture of himself ${ }_{i}$ did Mary tell John ${ }_{i}$ that she liked?

b. Which picture of himself ${ }_{i}$ does it seem to Jane that Mary told $\mathrm{John}_{i}$ that she liked?

c. *Which picture of himself ${ }_{i}$ does Mary seem to Jane to have told John ${ }_{i}$ that she liked?

Thus, when the data in (19) are taken into account, the contrast between (14a) and (14b) does not constitute an argument for punctuated paths. In the next section, however, we present some new facts that we believe count as evidence for punctuated paths, namely reconstruction data from Norwegian (cf. Bentzen 2007). 


\section{New empirical evidence: Reconstruction in Norwegian}

First consider example (20). There are two readings for this example, one in which the quantified DP some girls has surface wide-scope over the adverb probably, yielding the reading that some girls are probably such that they will come to the party. Alternatively, the quantified DP may be reconstructed into a position between probably and come (possibly its base position, indicated by $t$ ), yielding the reading that it is probable that some girls are such that they will come to the party.

(20) Noen jenter vil sannsynligvis $t$ komme på festen.

(Norw.)

some girls will probably come on party.the

'Some girls will probably come to the party.'

The availability of the second reading makes it clear that reconstruction somewhere between probably and come is possible, but (20) does not identify the exact location of $t$. An important question in this respect is whether $t$ could be associated with any one of the relevant positions between probably and come (a uniform view of paths), or with just a selection of these positions (a punctuated view of paths). To probe whether or not an intermediate reconstruction site is indeed available, we first need to construct a context in which reconstruction into the base position can be excluded semantically. Example (21) provides exactly such a context.

... at noen gutter sannsynligvis $t^{\prime}$ må ha $t$ dratt til Roma.
that some boys probably must have gone to Rome

(Norw.)

'... that some boys probably must have gone to Rome.'

This example is three-ways ambiguous. The quantified DP some boys may get a surface wide-scope reading: Some boys are such that they probably must have gone to Rome. A second reading is possible if the DP reconstructs into a position between the adverb probably and the modal must. This yields the reading that it is probable that some boys are such that they must have gone to Rome. In the third reading, the DP reconstructs below must, yielding the reading that it is probable that it must be the case that some boys have gone to Rome.

Now let us exclude reconstruction into the base position in example (21) by introducing a variable. Since binding requires scope, we can force the subject to take scope at least as high as some other phrase, by forcing the subject to bind into this other phrase. In (22) the variable binder 'på eget initiativ' (on their own initiative) forces the subject 'noen jenter' (some girls) to at least scope above it, thus excluding reconstruction into the base position, as indicated by ${ }^{\#} t$.

(22) Noen jenter vil sannsynligvis $* t^{\prime \prime}$ på eget initiativ ${ }^{\#} t$ komme på festen. some girls will probably on own initiative come on party.the 'Some girls will probably on their own initiative come to the party.' 
What we are interested in is, of course, the availability of the intermediate reading. ${ }^{7}$ The availability of the intermediate reading, or its absence, provides information about the availability (or lack thereof) of an intermediate site for scopereconstruction of the moved subject. As said above, reconstruction into the DP's base position is blocked for reasons of binding in (22), as the DP needs to bind the reflexive own inside the adverb on their own initiative. If paths were uniform, it should still be possible to reconstruct the subject in a position in between probably and on their own initiative. However, it turns out that only a wide-scope reading of the DP is available in (22), suggesting that there is no reconstruction site for the subject at the location of $t^{\prime \prime}$.This observation thus indicates that there is no intermediate trace of the subject in the position of the starred $t^{\prime \prime}$, and, in conjunction with the observation that intermediate reconstruction is available at $t^{\prime}$ in (21), this constitutes support for the assumption that paths are punctuated.

The contrast between (21) and (22) suggests that the positions of $t^{\prime}$ in (21) and of $t^{\prime \prime}$ in (22) are not identical. We take $t^{\prime}$ in (21) to be positioned lower than the location of the variable binder on their own initiative in (22). Support for this analysis of the contrast between (21) and (22) comes from the even more telling contrast between (21) and (23). The examples form a minimal pair; the only difference is the addition of 'mot sin vilje' (against his own will) to the right of 'sannsynligvis' (probably) in (23).

(23) $\ldots$ at noen gutter sannsynligvis $* t^{\prime \prime}$ mot $\sin$ vilje ${ }^{\prime} t^{\prime}$ må ha ${ }^{\#} t$ dratt that some boys probably against REFL will must have gone til Roma.

to Rome

'... that some boys probably must have gone to Rome against their will.'

In (23) we have three potential candidates for reconstruction sites; $t, t^{\prime}$, and $t^{\prime \prime}$. As shown in (21), reconstruction to $t$ and $t^{\prime}$ is normally possible. However, in (23) reconstruction of the subject to a position below the added PP is impossible, since this would leave the possessive anaphor unbound. This explains why reconstruction to the lower two trace positions ( $t$ and $t^{\prime}$ ) is impossible. In contrast, however, (23) confirms what we argued for (22), namely that reconstruction to $t^{\prime \prime}$ is not possible. If there were an intermediate landing site in the position of $t^{\prime \prime},(23)$ should still be ambiguous between a reading where the subject takes scope over 'sannsynligvis' and a reading where 'sannsynligvis' takes scope over the subject. However, the example is unambiguous: only the wide scope reading of the subject is available. This suggests, again, that there is no trace in the position of $t^{\prime \prime}$; the missing intermediate position $t$ " is a 'punctuation' in the path between the base and the surface

7. A potential challenge to the argument we are developing here might come from the treatment of scope phenomena in the absence of syntactic scope by way of quantification over semantic objects of higher types (see Engdahl (1980; 1986), Chierchia (1993), Kratzer (1998), Sauerland (1998; 2004) and in particular the application of these ideas to scopal interactions between quantifiers and modals in Abels and Martí (2008)). 
position, and this constitutes an argument against a uniform view of movement paths.

Although reconstruction below the PP containing the possessive anaphor is monotonically unavailable (because of the monotonicity of scope and binding domains), the fact that there is no reconstruction site in between 'sannsynligvis' and the PP makes the pattern overall non-monotonic. In our view, these Norwegian constructions therefore constitute the appropriate kind of test for the availability of intermediate reconstruction sites, and we believe that the data illustrated in this section provide real support for the claim that movement paths are punctuated rather than uniform.

\section{Other kinds of evidence}

A different line of argumentation for the punctuated nature of movement paths is implicit in Baltin (2007), and Aelbrecht (2008). Both authors are concerned with patterns where phrases are missing and typical diagnostics for the presence of covert syntactic structure yield contradictory results. Baltin discusses properties of the British English do in constructions like (24); Aelbrecht - the properties of null complements of modals in Dutch, (25). ${ }^{8}$ All English examples in this section are taken from Baltin (2007), all Dutch examples from Aelbrecht (2008) unless noted otherwise.

(24) John will run the race and Bill will do, too.

(25) Wie wast er vanavond af? who washes there tonight off B: Ik kan niet. (Dutch) 'Who is doing the dishes tonight? - I can't.'

One of the problems raised by these constructions is that there is contradictory evidence regarding the syntactic complexity of the missing VP. On the one hand, there is evidence that the British English do and the Dutch modals in question do not assign thematic roles to the subjects in (24) and (25): they are raising verbs, (26a). The surface subject can, in fact, be generated in the underlying object position, as shown by the unaccusative example (26b) and the passive (27). This provides evidence that the missing VP in these constructions is syntactically represented. ${ }^{9}$

(26) a. John might seem to enjoy that, and Fred might do__, too.

b. The river will freeze solid, and the lake will do, too.

8. Aelbrecht shows that the phenomenon is limited and does not occur with epistemic modals. This complication is unimportant here.

9. Baltin also shows that the British English do construction allows for sloppy readings of pronouns within the missing VP, which he takes to be a further argument for the assumption that the VP must be syntactically represented. 
(27) Die broek moet niet gewassen worden vandaag, mar die rok moet wel. that pants must not washed become today but that skirt must PRT 'Those pants don't need to be washed, but that skirt does.'

When it comes to $w h$-movement on the other hand, neither British English do nor the null complement of Dutch modals allows the construal of a $w h$-trace inside of the elided VP, (28). This contrasts with the behavior of VP ellipsis in English, which does allow the construal of a $w h$-trace in the ellipsis site, (29). ${ }^{10}$

(28) a. *Although I don't know who John will visit, I do know who Fred will do_

b. Ik weet niet wie Kaat moet uitnodigen, maar ik weet wel

I know not who Kate must invite but I know AFF wie ze niet moet $*$ (uitnodigen).

who she not must invite

'I don't know who Kate should invite, but I do know who she shouldn't.'

(29) Although I don't know who John will visit, I do know who Fred will

Baltin and Aelbrecht conclude that an ellipsis analysis for these kinds of cases is called for to accommodate the evidence in favor of covert syntactic structure. The challenge, then, is to account for the fact that some movements can escape the ellipsis site, while others cannot. Though both analyses differ considerably in terms of implementation, they also have a number of properties in common. The property that is crucial for this paper, which both analyses share, can be formulated as the generalization in (30).

(30) Baltin and Aelbrecht's Generalization:

Movement from an ellipsis site may be licensed only if there is an intermediate landing site for the moving element that is both outside of the ellipsis site and dominated by the maximal projection of the head which triggers/licenses ellipsis.

Baltin now assumes that the $\mathrm{vP}$ assumed by many minimalists is split into a $\mathrm{vP}$ and voiceP, where the latter dominates the former. VoiceP is not only higher than vP, it also counts as a phase, while vP does not. vP comes in various flavors (agentive, non-agentive, etc.), but it is always present as it carries the features that categorize the category-less root (see Marantz (1997)). Baltin further assumes that there is always a trace of the subject in [Spec, $\mathrm{VP}]$, but it does not host traces of $w h$ movement. The specifier positions of voiceP on the other hand count as a phase edge and host traces of all types of movement out of the domain of voice. The trig-

10. Baltin also discusses quantifier raising. Aelbrecht - scrambling. Similar facts have been observed about the interaction of subject raising and clitic climbing with restructuring verbs in Romance (see, e.g. Depiante (2000), Cinque (2006)). Baltin claims that NP ellipsis in English should be analyzed similarly. 
ger for ellipsis under British English do is do itself, a $v$. The result is deletion of do's complement. By Baltin and Aelbrecht's generalization this accounts for why only A-movement can escape from the ellipsis site with British English do. VP ellipsis on the other hand involves ellipsis of the complement of voiceP. Since voiceP provides escape hatch positions for all sorts of movement, it is correctly predicted to allow both A-movement and wh-movement from the ellipsis site.

Similarly, Aelbrecht assumes that Dutch modals select non-finite TPs. Their head $\mathrm{T}^{\circ}$ is null. Its complement (VoiceP) gets deleted. Deletion is licensed by the modal that takes the TP as its complement. Since [Spec,TP] provides a landing site for A-movement but not for $w h$-movement and the modal itself does not host intermediate traces of $w h$-movement either, the facts follow as under Baltin's analysis. ${ }^{11}$

To the extent that Baltin's and Aelbrecht's analyses are on the right track, they provide evidence for the punctuated nature of movement paths. Both rely crucially on (30), which is not stateable if movement paths are uniform.

\section{Concluding remarks}

In this paper we have sketched the logic that arguments should take which purport to argue for punctuated and against uniform movement paths. In particular, nonmonotonic reconstruction patterns can lend support to the position that movement paths are punctuated, a position that has long formed part of the orthodoxy of Chomskyan syntactic theory without being backed by truly decisive arguments. Contra Boeckx (2008) we hold that this is an empirical issue.

Finally, although we concede that the evidence for punctuated paths originally proposed in Abels (2003) does not stand up to scrutiny, the case for punctuated paths can still be made. We illustrated this using the interaction of scope reconstruction and binding in Norwegian. The Norwegian examples suggest that a moving element only makes pit-stops in selected positions along the movement path.

Since the Norwegian facts discussed here are fairly subtle and subject to a certain amount of variation, we conclude noting that the true issues involved by the punctuated paths hypothesis have barely been probed and that the paucity of compelling evidence in favor of the punctuated paths position remains as a challenge to those who wish to uphold it.

\section{References}

Abels, Klaus (2003). Successive Cyclicity, Anti-locality, and Adposition Stranding. Doctoral dissertation, University of Connecticut.

Abels, Klaus; Martí, Luisa (2008). "All split scope is not alike.” Talk presented at Sinn und Bedeutung 13, Stuttgart.

11. Notice that it will not do to deny that a movement relation is involved in what is traditionally analyzed as A-movement and to claim that no movement is possible out of the ellipsis site under British English do and Dutch modals. The reason this is insufficient are the Norwegian facts discussed earlier in the paper, which showed that movement paths are punctuated even for A-movement. 
Aelbrecht, Lobke (2008). "Dutch modal complement ellipsis and English VPE." Talk presented at CGSW 23, Edinburgh.

Baltin, Mark R. (2007). "Deletion versus pro-forms: A false dichotomy?" Ms. NYU. Barss, Andrew (1986). Chains and Anaphoric Dependence: On Reconstruction and its Implications. Doctoral dissertation, MIT.

Barss, Andrew; Lasnik, Howard (1986). "A note on anaphora and double objects." Linguistic Inquiry 17: 347-354. [Reprinted in: Lasnik, Howard (ed.). Essays on anaphora. Dorrecht: Kluwer, pp. 143-148].

Bentzen, Kristine (2007). Order and Structure in Embedded Clauses in Northern Norwegian. Doctoral dissertation, University of Troms $\varnothing$, Norway.

Boeckx, Cedric (2001). Mechanisms of Chain Formation. Doctoral dissertation, University of Connecticut.

Boeckx, Cedric (2008). Understanding Minimalist Syntax: Lessons from Locality in Long-Distance Dependencies, vol. 9 of Generative Syntax. Blackwell Publishing.

Bošković, Željko (2007). "On the locality and motivation of move and agree: An even more minimal theory." Linguistic Inquiry 38: 589-644.

Bouma, Gosse; Molouf, Robert; Sag, Ivan A. (2001). "Satisfying constraints on extraction and adjunction." Natural Language and Linguistic Theory 19 1: 1-65.

Chierchia, Gennaro (1993). "Questions with quantifiers." Natural Language Semantics 13: 181-234.

Chomsky, Noam (1973). Conditions on transformations. In S. R. Anderson and P. Kiparsky, editors, A Festschrift for Morris Halle, pages 232-286. Holt, Rinehart and Winston, New York.

Chomsky, Noam (1986). Barriers. Cambridge, Ma.: MIT Press.

Chomsky, Noam (2000). Minimalist inquiries: The framework. In R. Martin, D. Michaels, and J. Uriagereka, editors, Step by Step: Essays on Minimalism in Honor of Howard Lasnik, pages 89-155. MIT Press, Cambridge, MA.

Chomsky, Noam; Lasnik, Howard (1993). "The theory of principles and parameters." In: Jacobs, Joachim; von Stechow, Arnim; Sternefeld, Wolfgang; Vennemann, Theo (eds.). Syntax: An International Handbook of Contemporary Research. Berlin: Walter de Gruyter, vol. 1, pp. 506-569.

Cinque, Guglielmo (1990). Types of A'-Dependencies. MIT Press, Cambridge, MA. Cinque, Guglielmo (2006). Restructuring and Functional Heads. Oxford Studies in Comparative Syntax: The Cartography of Syntactic Structures. Oxford and New York: Oxford University Press.

Cresti, Diana (1995). "Extraction and reconstruction.” Natural Language Semantics 3 1: 79-122.

Depiante, Marcela (2000). The Syntax of Deep and Surface Anaphora: A Study of Null Complement Anaphora and Stripping/Bare Argument Ellipsis. Doctoral dissertation, University of Connecticut, Storrs, CT.

Engdahl, Elisabet (1980). The Syntax and Semantics of Questions in Swedish. Doctoral dissertation, University of Massachusetts, Amherst, Mass.

Engdahl, Elisabet (1986). Constituent Questions - The Syntax and Semantics of Questions with Special Reference to Swedish. Dordrecht, Boston, Lancaster, Tokyo: Reidel.

Fox, Danny (2000). Economy and Semantic Representation. Cambridge, Mass.: MIT Press and MITWPL. 
Frampton, John (1999). "The fine structure of $w h$-movement and the proper formulation of the ECP." The Linguistic Review 16 1: 43-61.

Giorgi, Alessandra; Longobardi, Giuseppe (1990). The Syntax of Noun Phrases. Cambridge: Cambridge University Press.

Kratzer, Angelika (1998). "Scope or pseudoscope?" In: Rothstein, Susan D. (ed.). Events in Grammar. Kluwer Academic Publishers, pp. 163-197.

Larson, Richard K. (1988). "Light predicate raising." Tech. rep., Center for Cognitive Science, MIT, Cambridge, Mass.

Marantz, Alec (1997). "No escape from syntax.” In: Dimitriadis, Alexis; Siegel, Laura (eds.). Proceedings of the 21st Annual Penn Linguistics Colloquium. University of Pennsylvania Working Papers in Linguistics, vol. 4.2.

McCloskey, James (1979). Transformational Syntax and Model Theoretic Semantics: A Case Study in Modern Irish. Synthese Language Library. D. Dordrecht, Boston, and London: Reidel Publishing Company.

McCloskey, James (1990a). Clause Structure, Ellipsis and Proper Government in Irish. Syntax research center, Cowell College, University of California at Santa Cruz., Santa Cruz, Cali.

McCloskey, James (1990b). "Resumptive pronouns, A'-binding, and levels of representation in Irish." In: Hendrick, Randall (ed.). The Syntax of the Modern Celtic Languages. Syntax and Semantics 23, San Diego: Academic Press, pp. 199-248.

McCloskey, James (2002). "Resumption, successive cyclicity, and the locality of operations." In: Epstein, Samuel David; Seely, T David (eds.). Derivation and Explanation in the Minimalist Program. Malden, MA and Oxford, UK: Blackwell, pp. 184-226.

Nissenbaum, John (2001). Investigations of Covert Phrasal Movement. Doctoral dissertation, MIT.

Noonan, Máire (1997). "Functional architecture and wh-movement: Irish as a case in point.” Canadian Journal of Linguistics 42: 111-139.

Sauerland, Uli (1998). The Meaning of Chains. Doctoral dissertation, MIT, Cambridge, Mass.

Sauerland, Uli (2004). “The interpretation of traces." Natural Language Semantics 12: 63-127.

Starke, Michal (2001). Move Dissolves into Merge: A Theory of Locality. Doctoral dissertation, University of Geneva.

Takahashi, Daiko (1994). Minimality of Movement. Doctoral dissertation, University of Connecticut.

Torrego, Esther (1983). "More effects of successive cyclic movement." Linguistic Inquiry 14: 561-565.

Torrego, Esther (1984). "On inversion in Spanish and some of its effects". Linguistic Inquiry 15: 103-129.

Uribe-Etxebarria, Myriam (1992). "On the structural positions of subjects in Spanish, and their consequences for quantification." In: Lakarra, Joseba A.; de Urbina, Jon Ortiz (eds.). Syntactic Theory and Basque Syntax. San Sebastian: ASJU, pp. 447-493. 